\title{
BMJ Open Post-traumatic stress disorder in adult victims of cluster munitions in Lebanon: a 10-year longitudinal study
}

\author{
Jawad Fares, ${ }^{1,2}$ Souheil Gebeily, ${ }^{1,3}$ Mohamad Saad, ${ }^{1,4}$ Hayat Harati, ${ }^{1}$ \\ Sanaa Nabha, ${ }^{1}$ Najwane Said, ${ }^{1}$ Mohamad Kanso, ${ }^{1,5}$ Ronza Abdel Rassoul, ${ }^{1,6}$ \\ Youssef Fares ${ }^{1,7}$
}

To cite: Fares J, Gebeily S, Saad M, et al. Post-traumatic stress disorder in adult victims of cluster munitions in Lebanon: a 10-year longitudinal study. BMJ Open 2017;7:e017214. doi:10.1136/ bmjopen-2017-017214

- Prepublication history and additional material for this paper are available online. To view please visit the journal online (http://dx.doi.org/10.1136/ bmjopen-2017-017214)

Received 7 April 2017 Revised 24 May 2017 Accepted 30 May 2017

CrossMark

For numbered affiliations see end of article.

\section{Correspondence to}

Dr Jawad Fares;

jyf04@mail.aub.edu and Prof.

Youssef Fares;

yfares@ul.edu.lb

\section{ABSTRACT}

Objective This study aims to explore the short-term and long-term prevalence and effects of post-traumatic stress disorder (PTSD) among victims of cluster munitions.

Design and setting A prospective 10-year longitudinal study that took place in Lebanon.

Participants Two-hundred-and-forty-four Lebanese civilian victims of submunition blasts, who were injured in 2006 and were over 18 years old, were interviewed. Included were participants who had been diagnosed with PTSD according to the Diagnostic and Statistical Manual of Mental Disorders, 5th Edition (DSM-5) and the PTSD Checklist - Civilian Version in 2006. Interviewees were present for the 10-year follow-up.

Main outcome measures PTSD prevalence rates of participants in 2006 and 2016 were compared. Analysis of the demographical data pertaining to the association of long-term PTSD with other variables was performed. p Values $<0.05$ were considered statistically significant for all analyses $(95 \% \mathrm{Cl})$

Results All the 244 civilians injured by cluster munitions in 2006 responded, and were present for long-term follow-up in 2016. The prevalence of PTSD decreased significantly from $98 \%$ to $43 \%$ after 10 years $(p<0.001)$. A lower long-term prevalence was significantly associated with male sex $(p<0.001)$, family support $(p<0.001)$ and religion $(p<0.001)$. Hospitalisation $(p=0.005)$ and severe functional impairment $(p<0.001)$ post-trauma were significantly associated with increased prevalence of long-term PTSD. Symptoms of negative cognition and mood were more common in the long run. In addition, job instability was the most frequent socioeconomic repercussion among the participants (88\%).

Conclusions Psychological symptoms, especially PTSD, remain high in war-affected populations many years after the war; this is particularly evident for Lebanese civilians who were victimised by cluster munitions. Screening programmes and psychological interventions need to be implemented in vulnerable populations exposed to war traumas. Officials and public health advocates should consider the socioeconomic implications, and help raise awareness against the harm induced by cluster munitions and similar weaponry.

\section{INTRODUCTION}

There have often been severe damaging psychiatric injuries among those who survive

\section{Strengths and limitations of this study}

- This is the first longitudinal study to analyse posttraumatic stress disorder (PTSD) in victims of cluster munition explosions, which helps in better understanding the course and prognosis of PTSD in these individuals.

- The DSM-5 criteria for PTSD were adopted, the PTSD Checklist - Civilian Version was used to aid in the diagnosis and a higher cut-off score was implemented to minimise false positives.

- Functional impairment was measured using the Fares Scale of injuries due to cluster munitions, which makes it easier to determine the true effects of cluster munitions and project on the mental health service needs.

- More demographical data on health and socioeconomic outcomes could have been collected.

- The female sample size of our study may have contributed to the lack of significant differences in some of the outcomes.

blasts. The 2006 Israeli-Lebanese conflict led to a large number of Lebanese civilians subjected to war-related psychological and biomechanical traumas. The war continues to haunt its survivors many years after it has ended.

Cluster munitions are a form of air-dropped or ground-launched explosive weapons that release or eject smaller submunitions over wide areas (figure 1). These weapons have been extensively used by the Israeli forces in southern Lebanon, and are currently dispersed over vast Lebanese lands impacting its inhabitants. ${ }^{12}$

Many states perceive cluster munitions as a main military equity that increases the efficiency of suppressing, killing or destroying multiple targets within a specified area. However, often, when they have been used near populated areas, civilians have died or got injured, either as a direct result of the attack and its area effect, or as a result 


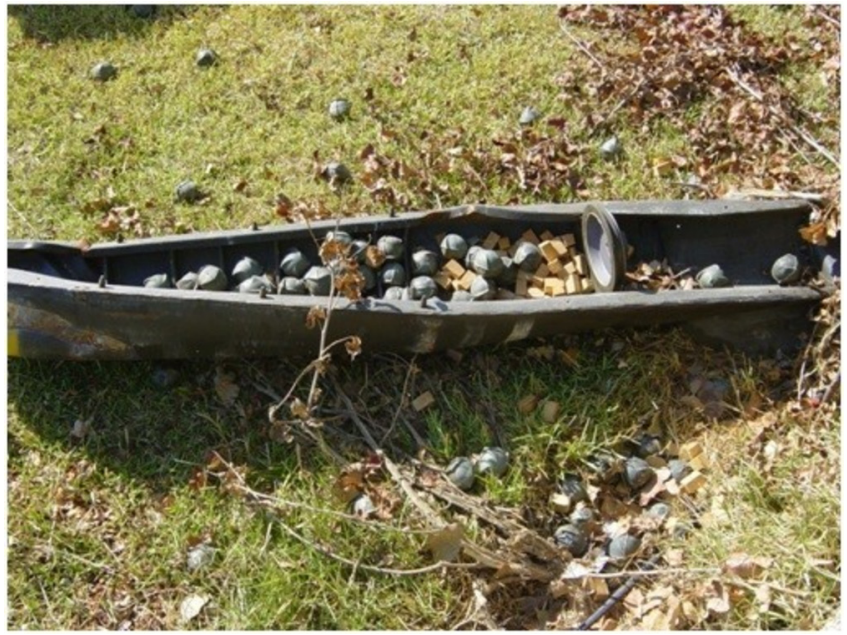

Figure 1 A cluster munition containing numerous undetonated submunitions in South Lebanon.

of postconflict unexploded submunitions. ${ }^{1-11}$ Unexploded submunitions can kill or maim civilians and/ or unintended targets long after a conflict has ended, and are costly to locate and remove. ${ }^{1}$ In comparison to other ordnances of war, the failure rate of cluster munitions is striking. In 2006, four million submunitions were dropped over Lebanese soil; more than one million of which remained unexploded. ${ }^{12}$

Submunitions inflict various injuries due to their easily 'pickable' nature. Biomechanical injuries resulting from cluster munitions have been discussed in a series of research articles; ${ }^{1-8}$ however, psychological tribulations remain to be explored. Post-traumatic stress disorder (PTSD) is a mental health problem that an individual may develop after experiencing or witnessing a life-threatening event, like combat, a natural disaster, a car accident or sexual assault. ${ }^{13}$ PTSD affects $7 \%-8 \%$ of the general population at some point during their lifetime; ${ }^{14}$ however, the prevalence is much higher among certain subgroups, including active-duty military personnel, and civilians exposed to blast injuries and war-related traumas. ${ }^{14}$

Submunition blasts can affect mental health, yet largescale studies that focus on the short-term and long-term impact are missing. Such information may help screening programmes in targeting high-risk populations and raise awareness against the harm induced by cluster munitions and similar weaponry. Therefore, this study aims to explore the short-term and long-term prevalence and effects of PTSD among adult victims of cluster munition explosions in Lebanon.

\section{MATERIALS AND METHODS \\ Study design}

This was a prospective 10-year longitudinal study of victims of cluster munitions who got injured after the 2006 Israeli-Lebanese conflict. The study took place over two phases: the first phase, studying the short-term prevalence of PTSD, was in 2006, and the second phase, exploring the long-term outcome of PTSD, took place in 2016. The submunition victims were first telephoned and asked if they were willing to conduct an interview on their psychological state postinjury. They were also asked if they preferred to be interviewed over the telephone or in the clinic. Almost all victims preferred to be interviewed in the clinic for the first time. Ten years after the first interview, the victims were contacted by telephone and again asked whether they preferred to be interviewed over the telephone or in the clinic. Almost half of the participants were not interested in presenting to the clinic, and so, many of these follow-up interviews were conducted over the telephone.

\section{Participants}

All the 244 Lebanese civilian victims, who were aged 18 years and above, and were injured by cluster munitions were interviewed. To be included, participants must be mentally competent, have met the Diagnostic and Statistical Manual of Mental Disorders, 5th Edition (DSM-5) criteria for PTSD and present with symptoms that lasted more than 1 month (to rule out acute stress disorder). It is worth mentioning that data from interviews collected in 2006 were adapted to the new DSM- 5 after its release in 2013. Military personnel, casualties presenting with injuries not caused by submunitions or those who recently had another traumatic event within a month were excluded. In addition, those who had PTSD symptoms resulting from other traumatic events that occurred in their life were also excluded from the study. The participants must be present for follow-up as well.

\section{Assessment}

All casualties were interviewed for the first time at least 1 month after the injury, in order to fall within the DSM-5 definition of PTSD, and no more than 9 months after the injury, in order to avoid a possible aggravated clinical expression as the time grew near the anniversary. The disturbance must have caused significant distress or impairment in the individual's social interactions, capacity to work or other important areas of functioning. Functional impairment was measured by the Fares Scale of injuries due to cluster munition explosions (online supplementary appendix A). ${ }^{2}$ In addition, PTSD must not be the physiological result of another medical condition, medication, drugs or alcohol. To enhance reliability, interviews were conducted by a single trained neuropsychologist. After their first interview, participants were provided with a list of authorised institutions that provide psychological health services and hospitals/medical centres that have psychiatry departments to increase the benefits of the study. Follow-up interviews were conducted again after 10 years. The interviewer was kept blind to the type of interventions the injured survivors had received.

The PTSD Checklist (PCL) - Civilian Version for the Diagnostic and Statistical Manual of Mental Disorders, 4th Edition (DSM-IV) was used to aid in the diagnosis of PTSD among the participants. This questionnaire is 
a self-report measure that can be read by respondents themselves or be read to them either in person or over the telephone. ${ }^{15}$ It can be completed in approximately $5-10 \mathrm{~min}$. A total symptom severity score (range 17-85) can be obtained by summing the scores from each of the 17 items that have response options ranging from 1 'Not at all' to 5 'Extremely'. ${ }^{15}$ PCL can be scored to provide a presumptive diagnosis by determining whether the total severity score exceeds a given normative threshold. A higher cut point was considered to minimise false positives as it is recommended in settings with expected high rates of PTSD, such as specialty mental health clinics. $^{16-18}$ The Veterans Affairs National Center for PTSD suggested a PCL cut point score of $45 .{ }^{15}$ Although there is no civilian version corresponding to the PTSD Checklist for DSM-5 (PCL-5), preliminary validation studies by the Veterans Affairs National Center for PTSD suggests that optimal PCL-5 cut points appear to be 11-14 points lower than for PCL for DSM-IV cut-points, with closer to an 11-point difference for more stringent cut-offs. ${ }^{15}$ Response categories 3-5 (moderately or above) were treated as symptomatic, and responses 1-2 (below moderately) were considered as non-symptomatic. The questions were administered by the interviewer in Arabic after being translated by a certified translator. The translated questionnaire was deemed valid and reliable after being piloted among a sample of 10 patients with PTSD.

\section{Demographic and outcome variables}

The data collected were as follows: (1) Demographics: sex; mean age; age range; mean time since injury; hospitalisation data; and data on discharge from the emergency room; (2) PTSD-related variables: re-experiencing (recollection of the event through thoughts or perceptions, images, dreams, illusions or hallucinations, dissociative flashback episodes or intense psychological distress or reactivity to cues that symbolise some aspect of the event); avoidance (evasion of thoughts, feelings, or conversations associated with the event and/or avoidance of people, places, or activities that may trigger recollections of the event); negative cognitions and mood (inability to remember an important aspect of the event, persistent negative emotional state and persistent inability to experience positive emotions); arousal (irritable behaviour and angry outbursts, reckless or self-destructive behaviour, hypervigilance, exaggerated startle response, concentration problems and/or sleep disturbance); (3) Injury-related variables: severity of injury; and functional impairment; and (4) Personal and social repercussions: marital and family problems; job instability; and legal difficulties.

\section{Statistical analysis}

Data collected from the interviews were processed, and PCL scores were calculated for each individual; scores $\geq 45$ supported the diagnosis of PTSD. The PTSD prevalence rates of participants according to sex in 2006 and 2016 were compared by means of paired two-tailed $t$ tests. This
Table 1 Demographics of the adult Lebanese participants injured by cluster munitions and diagnosed with PTSD in $2006(n=239)$

\begin{tabular}{ll}
\hline Demographic trait & Number (\%) \\
\hline Male & $224(94)$ \\
Female & $15(6)$ \\
\hline Mean age (years) \pm SD & $27 \pm 4.3$ \\
\hline Age range (years) & $(18,67)$ \\
Mean time since injury (months) $\pm S D$ & $2.2 \pm 1.2$ \\
Hospitalised & $230(96)$ \\
Discharged from emergency room & $9(4)$ \\
Severe functional impairment* & $141(59)$ \\
Family support & $228(95)$ \\
Religious & $220(92)$ \\
\hline
\end{tabular}

*Severe functional impairment was measured using the Fares Scale of injuries due to cluster munition explosions (grades II-IV were considered severe).

PTSD, post-traumatic stress disorder.

test was used to account for the dependent (before and after) observations. It calculates the difference within each before-and-after pair of measurements, determines the mean of these differences and reports whether this mean of differences is statistically different than zero. Analysis of the demographical data pertaining to the association of long-term PTSD with other variables such as sex, religion, family support and hospitalisation, was performed using the $\chi^{2}$ test, as it tests the significance of association between two categorical variables. All statistical analyses were performed using the Statistical Package for Social Sciences, V.23.0 (SPSS, Chicago, Illinois, USA).

\section{RESULTS}

All the 244 civilians, aged 18 years and above, and injured by cluster munitions in 2006, responded and were present for long-term follow-up in 2016. Of 244, 239 individuals (98\%) were diagnosed with PTSD in 2006 and were the focus of our study $(n=239)$. Participants served as their own controls because matching a cohort of civilians injured by cluster munitions and having PTSD with a cohort of civilians injured by cluster munitions who do not have PTSD would have been difficult.

The mean age $( \pm \mathrm{SD})$ of the participants was $27( \pm 4.3)$ years, ranging from 18 years to 67 years. The mean time since injury $( \pm \mathrm{SD})$ was $2.2( \pm 1.2)$ months. The complete profile of the participants is displayed in table 1 .

Interestingly, the percentage of participants with PTSD was $98 \%$ in 2006 (239 of 244) and it significantly decreased to $43 \%$ in 2016 (105 of 244). The five individuals $(2 \%)$ who were not diagnosed with PTSD in 2006, did not develop it in 2016.

The distribution of answers in the PCL in the short term and long term are presented in online supplementary appendix B and supplementary appendix C, respectively. 
Table 2 Prevalence of PTSD among the 244 adult Lebanese victims of cluster munitions in 2006 and 2016 across the two sexes

\begin{tabular}{lccc}
\hline & $\begin{array}{l}\text { Diagnosed with } \\
\text { PTSD in 2006 }\end{array}$ & $\begin{array}{l}\text { Diagnosed with } \\
\text { PTSD in 2016 }\end{array}$ & p Value* \\
\hline Male & 224 & 91 & $<0.001$ \\
Female & 15 & 14 & 0.334 \\
Total & 239 & 105 & $<0.001$ \\
\hline
\end{tabular}

${ }^{*} p$ Value $<0.05$ indicates statistical significance.

PTSD, post-traumatic stress disorder.

The most common symptomatic responses that persisted in the long run were: (1) feeling very upset when something reminded of the stressful experience $(65 \%)$; (2) loss of interest in things that were previously enjoyable $(63 \%)$; and (3) feeling distant or cut-off from other people $(63 \%)$. The least common symptomatic responses that were present after 10 years were: (1) trouble falling or staying asleep (17\%); (2) feeling irritable or having angry outbursts (20\%); and (3) suddenly acting or feeling as if a stressful experience was happening again (20\%).

Among the participants, more men (94\%) than women $(6 \%)$ were diagnosed with PTSD in 2006. The number of men diagnosed with PTSD decreased significantly from 224 in 2006, to 91 in 2016 ( $\mathrm{p}<0.001)$. However, the number of women diagnosed with PTSD did not change significantly in the long run (table 2 ).

In the long run, family support $(\mathrm{p}<0.001)$ and religion $(\mathrm{p}<0.001)$ were significantly associated with decreased prevalence of PTSD. Hospitalisation postincident, opposed to being discharged from the emergency room, was significantly associated with increased prevalence of long-term PTSD $(p=0.005)$. Severe functional impairment was also significantly correlated with increased prevalence of long-term PTSD $(\mathrm{p}<0.001)$ (table 3).

Personal and socioeconomic repercussions of participants diagnosed with PTSD in the long run are presented in table 4.

\section{DISCUSSION}

This is the first longitudinal study to analyse PTSD in victims of cluster munition explosions. Overall, the prevalence of PTSD decreased significantly after 10 years. A lower long-term prevalence was significantly associated with male sex, family support and religion. Hospitalisation post-trauma and severe functional impairment were significantly associated with increased prevalence of longterm PTSD. Symptoms of negative cognition and mood were more common in the long run. In contrast, symptoms of arousal and re-experiencing were less common. Job instability was the most frequent socioeconomic repercussion among the participants in the long run.

The prevalence of PTSD in the Lebanese victims of cluster munitions was $98 \%$ in 2006. A previous study on PTSD in civilian populations from Lebanon showed
Table 3 Association of long-term PTSD (after 10 years) with variables such as family support, religion, hospitalisation and severity of injury in victims of cluster munitions $(n=239)$

\begin{tabular}{lrlll}
\hline & N & PTSD rate & SE & p Value* \\
\hline $\begin{array}{l}\text { Family support } \\
\text { Yes }\end{array}$ & 228 & 0.41 & 0.03 & $<0.001$ \\
No & 11 & 1.00 & 0 & \\
Religious & & & & \\
Yes & 220 & 0.39 & 0.03 & $<0.001$ \\
No & 19 & 1.00 & 0 & \\
Hospitalised & & & & \\
Yes & 230 & 0.46 & 0.03 & 0.005 \\
No & 9 & 0 & 0 & \\
Functional impairment† & & & \\
Yes & 141 & 0.74 & 0.04 & $<0.001$ \\
No & 98 & 0 & 0 & \\
\hline
\end{tabular}

${ }^{*} \mathrm{p}$ Value $<0.05$ indicates statistical significance.

†Functional impairment was measured using the Fares Scale of injuries due to cluster munition explosions (grades II-IV were considered severe).

PTSD, post-traumatic stress disorder.

a prevalence of $29.3 \%$ in the same year postwar. ${ }^{19}$ After 10 years, the prevalence of PTSD among our sample was found to be $43 \%$. A 2016 study has shown a PTSD prevalence of $23.4 \%$ in a survey of a southern Lebanese civilian sample. ${ }^{20}$ The striking difference in PTSD prevalence between studies within the same year can be attributed to the cluster munition injury that the participants of our study endured.

Previous studies that examined the prevalence of PTSD in other countries that had experienced war atrocities have shown lower prevalence of PTSD than our study. ${ }^{21-24}$ To examine the mental health and cognitive effects of war trauma on war survivors in Yugoslavia, Başoğlu et $a l^{21}$ found that $33 \%$ of survivors suffered from PTSD. De Jong $e t a l^{23}$ attempted to study the impact of trauma in postconflict low-income countries where people have survived multiple traumatic experiences. They found the prevalence rate of assessed PTSD to be $37.4 \%$ in Algeria, $28.4 \%$ in Cambodia, $15.8 \%$ in Ethiopia and $17.8 \%$ in Gaza. ${ }^{23}$ Priebe et $a l^{24}$ studied mental health in five countries of ex-Yugoslavia and found prevalence rates ranging

Table 4 Personal and socioeconomic repercussions in the 105 victims of cluster munitions diagnosed with PTSD, 10 years postinjury

\begin{tabular}{ll}
\hline Social repercussions & Number (\%) \\
\hline Marital and family problems & $21(20)$ \\
Job instability & $92(88)$ \\
Legal difficulties & $9(9)$ \\
\hline
\end{tabular}

PTSD, post-traumatic stress disorder. 
from $15.6 \%$ to $41.8 \%$ for anxiety disorders. The PTSD prevalence rate among victims of cluster munitions in our study is still higher than those reported in different samples from different countries, even after 10 years. As there might be a difference in the psychobiology of PTSD between victims of cluster munitions and civilians who were survivors of war, we compared our results to studies on civilians who sustained a traumatic injury. In a study by Ohry et $a l^{25}$ on patients with traumatic brain injury (TBI), 33\% met the criteria for PTSD diagnosis. Shalev et $a l^{26}$ found that $25.5 \%$ of injured trauma survivors met PTSD diagnostic criteria at the 6-month follow-up. Also, Mora $e t a l^{27}$ reported a PTSD prevalence of $32 \%$ in patients with explosion-related burns. Furthermore, a prospective study following traumatic events reported that $29.9 \%$ of survivors met the criteria for PTSD at 1 month, and $17.5 \%$ had PTSD at 4 months. ${ }^{28}$ The prevalence of PTSD among cluster munition victims was still much higher. We believe that the injuries resulting from cluster munition blasts are unique and different from other blast injuries.

Our study showed a significant drop in PTSD prevalence after 10 years of the trauma incident. Other studies have also shown that, with time, PTSD decreases in prevalence and severity. ${ }^{29}{ }^{30}$ Farhood $^{31}$ assessed the prevalence of PTSD in a general population from southern Lebanon in 2005, amid political turmoil in the country, and then compared it with a follow-up assessment done in 2007, on the same population. Findings revealed that PTSD symptoms in the sample dropped from $24.1 \%$ in 2005 to $17.9 \%$ in $2007 .{ }^{31}$ We believe that coping and having a support system lessen the effect of trauma events over time.

The most common long-term symptoms of PTSD were related to low mood and cognition. Several studies have shown the co-occurrence of depressive symptoms and PTSD early on after trauma. ${ }^{25}{ }^{27}$ 32-39 Furthermore, research has shown that the occurrence of depression during the months that follow a traumatic event is an important mediator of chronicity in PTSD. ${ }^{32} 3740$

In our study, the number of men injured by cluster munitions was much higher than that of women. The male predominance could be explained by the societal norms of men performing farming, grazing and other rural activities where submunitions could be scattered. ${ }^{6}$ Furthermore, the evacuation of women from the area during the war decreased the female casualties.

Female sex was associated with having PTSD after 10 years. This coincides with previous research studies that assert that female sex is a risk factor for PTSD. ${ }^{25} 27$ 32-39 The reason for this excess risk in women is not clear; however, some have proposed that women are more likely to perceive threatening events as stressful compared with men, ${ }^{41}{ }^{42}$ and consequently, this may affect their mental health. ${ }^{42}$

Our results show that victims hospitalised after biomechanical trauma were at increased risk for PTSD. Often, patients with PTSD present with both medical and psychiatric symptoms. Many studies have proposed that biomechanical injury in the setting of a psychologically traumatic event is a risk factor for PTSD ${ }^{43-45}$ Mollica $e t$ $a l^{46}$ detected higher rates of PTSD and depression in civilians who endured injuries with psychological trauma than other types of injury. Furthermore, Hoge et al. ${ }^{47}$ explored army soldiers who sustained a TBI, and found higher rates of PTSD and depression in those who concurrently had loss of consciousness. Moreover, a study by Schneiderman et $a t^{48}$ reported that the risk of developing PTSD was almost doubled by a probable TBI. It is worth mentioning that $59 \%$ of the participants in our study sustained injuries with severe functional impairment. Therefore, the type of injuries, the severity of functional impairment, and the personal and psychosocial stressors that come with the situation may play a role in strengthening the relationship between injury and PTSD.

Similarly to other studies in the literature, religion and social and familial support were negatively correlated to PTSD. ${ }^{49-53}$ It has been shown that a higher index of religious beliefs improves stress control and provides better psychological stability. ${ }^{49}$ Hasanović and Pajević ${ }^{49}$ assert that religion allows post-traumatic conflicts, typical for survivors of combat, to be better overcome. Copeland-Linder ${ }^{50}$ found that prayer diluted the impact of stress on physical health and decreased the symptoms of depression. In another study, social and family support and religious beliefs were all found to be protective against PTSD following war trauma and torture $;^{51}$ higher perceived social support was associated with higher positive emotions. ${ }^{51}$ We affirm that family support and religion help in overcoming post-trauma personal and psychosocial tribulations and lead to an improvement in mental health.

Our results showed that personal and socioeconomic effects were present in the participants diagnosed with PTSD after 10 years. Studies have shown that the effects of PTSD on the family of the victim and the society at large are significant. ${ }^{1258}$ Besides the emotional and psychological symptoms of PTSD, individuals with PTSD are more likely to experience marital and family problems, ${ }^{5455}$ job instability, ${ }^{56}$ legal difficulties ${ }^{5457}$ and physical health problems. ${ }^{58} 59$

In the long run, job instability was the most common socioeconomic repercussion. Other studies have also shown that unemployment and low functionality are associated with lower mental health conditions, namely PTSD. ${ }^{20} 56$ We believe that the economic costs of PTSD are attributable to lost work productivity; the severity of the injury and the associated functional impairment definitely play a role.

Healthwise, Hoge et $a b^{60}$ add that individuals with a history of PTSD are at a heightened risk for developing cardiovascular disorders, respiratory disorders, gastrointestinal disorders, infectious diseases, nervous system disorders and autoimmune disorders. In addition, they are more likely to experience anxiety, depression, substance use and other mental health disorders. ${ }^{32} 4954576162$

In our study, we aimed to identify the prevalence of PTSD and associated factors following cluster munition-related 
injuries by adopting a longitudinal design and paying close attention to optimising the research methodology. The longitudinal nature of the study helped in better understanding the course and prognosis of PTSD in these individuals. This form of design can also elucidate the most effective screening and treatment regimens and factors that influence recovery. The study can be considered representative as we were capable of reaching all of the individuals who met our inclusion criteria. In addition, all individuals were reachable for follow-up. Due to the lack of consistent definitions of PTSD, we adopted the DSM-5 criteria for PTSD and used the PCL as a tool to aid in the diagnosis. We used a higher cut-off score to minimise false positives. Moreover, we measured functional impairment using the Fares Scale of injuries due to cluster munitions. To our knowledge, functional impairment measures have not been incorporated into previous case definitions, which makes it difficult to determine the true effects of cluster munitions and project on the mental health service needs. Furthermore, we studied the nature and severity of the impairment along multiple dimensions to include work, family and social relationships. However, the instrument of measure used differs from one study to another and can lead to varying degrees of PTSD reporting. As many of the follow-up interviews were held over the telephone, we were limited by time. More demographical data on health, treatment and socioeconomic outcomes could have been gathered. In addition, information on comorbid mental health conditions like depression, anxiety, sleep disorders, eating disorders, substance use disorders and suicide could have been collected.

More research is needed to study the interaction between trauma exposure, pre-existing psychological and biological vulnerabilities, and the post-trauma environment. Future research can better measure the impact of comorbid factors such as aggression, risk-taking behaviours and physical symptoms to comprehend all the effects of war-related trauma. As the prevalence of PTSD and other mental health conditions is high in the Lebanese population, advanced neurobiological and neuropsychological studies are needed to better understand the pathophysiology of PTSD and how genetic and environmental factors tally up to induce it.

\section{IMPLICATIONS AND CONCLUSIONS}

This is the first longitudinal study to analyse PTSD in victims of cluster munition explosions. Shortly posttrauma, $98 \%$ of those injured by cluster munitions were diagnosed with PTSD. In a 10-year follow-up, $43 \%$ still had the disorder. Overall, the prevalence of PTSD decreased significantly after 10 years. Male sex, family support and religion are possible protective factors against PTSD. Whereas, hospitalisation post-trauma and severe functional impairment are possible risk factors for PTSD. Symptoms of negative cognition and mood were more common in the long run. In contrast, symptoms of arousal and re-experiencing decreased in prevalence with time. PTSD is associated with numerous deleterious outcomes, and its costs on the victims, their immediate family and society at large are substantial.

Intervention and screening programmes should target vulnerable populations in Lebanon. Public health advocates and governmental officials should run campaigns to raise awareness against cluster munitions, and educate people on their shapes, characteristics and dangers. Moreover, municipal efforts and regional projects that aim to demine unexploded submunitions should be funded and supported by governmental and non-governmental organisations.

Laws should be passed and enforced to ban the use of these detrimental weapons that have negative effects on human, societal and ecological levels. More countries should join the Convention on Cluster Munitions, as these vicious weapons blindly and disproportionately hurt innocent civilians, and fail to comply with the well established universal laws controlling conflict and war today.

\section{Author affiliations}

${ }^{1}$ Neuroscience Research Center, Faculty of Medical Sciences, Lebanese University, Beirut, Lebanon

${ }^{2}$ Faculty of Medicine, American University of Beirut, Beirut, Lebanon

${ }^{3}$ Department of Neurology, Faculty of Medical Sciences, Lebanese University, Beirut, Lebanon

${ }^{4}$ Division of Statistical Genetics, Department of Biostatistics, University of Washington, Seattle, Washington, USA

${ }^{5}$ Department of Emergency Medicine, American University of Beirut Medical Center, Beirut, Lebanon

${ }^{6}$ UMR 1141, Hôpital Robert Debré, Institut National de la Santé et de la Recherche Médicale, Paris, France

${ }^{7}$ Department of Neurosurgery, Faculty of Medical Sciences, Lebanese University, Beirut, Lebanon

Twitter@nrc_lu

Contributors JF and YF designed the study and collected the data. JF carried out the statistical analyses and drafted the manuscript. All authors contributed to the analysis of the results. All authors critically revised the manuscript for important intellectual content. JF and YF are the primary investigators and guarantors of the study.

Funding This research was funded by a grant from the Central Administration of the Lebanese University, Beirut, Lebanon.

Competing interests None declared.

Patient consent Detail has been removed from these case descriptions to ensure anonymity. The editors and reviewers have seen the detailed information available and are satisfied that the information backs up the case the authors are making.

Ethics approval Institutional Review Board at the Faculty of Medical Sciences, Lebanese University, Beirut, Lebanon.

Provenance and peer review Not commissioned; externally peer reviewed. Data sharing statement Supplementary material is provided.

Open Access This is an Open Access article distributed in accordance with the Creative Commons Attribution Non Commercial (CC BY-NC 4.0) license, which permits others to distribute, remix, adapt, build upon this work non-commercially, and license their derivative works on different terms, provided the original work is properly cited and the use is non-commercial. See: http://creativecommons.org/ licenses/by-nc/4.0/

(c) Article author(s) (or their employer(s) unless otherwise stated in the text of the article) 2017. All rights reserved. No commercial use is permitted unless otherwise expressly granted. 


\section{REFERENCES}

1. Hoteit A, Fares J. Psycho-environmental tribulations arising from cluster munitions in South Lebanon. Sci-Afric J Sci Issues Res Essays 2014;2:469-73.

2. Fares Y, Fares J. Anatomical and neuropsychological effects of cluster munitions. Neurol Sci 2013;34:2095-100.

3. Abou-Abbass $\mathrm{H}$, Bahmad H, Ghandour $\mathrm{H}$, et al. Epidemiology and clinical characteristics of traumatic brain injury in Lebanon: A systematic review. Medicine 2016;95:e5342.

4. Bedrossian N, Haidar M, Fares J, et al. Inflammation and elevation of Interleukin-12p40 in patients with Schizophrenia. Front Mol Neurosci 2016;9.

5. Fares Y, Ayoub F, Fares J, et al. Pain and neurological sequelae of cluster munitions on children and adolescents in South Lebanon. Neurol Sci 2013;34:1971-6.

6. Fares Y, El-Zaatari M, Fares J, et al. Trauma-related infections due to cluster munitions. J Infect Public Health 2013;6:482-6.

7. Fares Y, Fares J. Neurosurgery in Lebanon: history, development, and future challenges. World Neurosurg 2017;99.

8. Fares Y, Fares J, Gebeily S. Head and facial injuries due to cluster munitions. Neurol Sci 2014;35:905-10.

9. Hoteit A. War against architecture, identity and collective memory. Int J Dev Res 2015;5.

10. Hoteit A. Role of the landscape in the preservation of collective memory and the enhancement of national belonging. Canadian Social Science 2015;11:42.

11. Hoteit A. Architectural education in the Arab world and its role in facing the contemporary local and regional challenges. Canadian Social Science 2016;12:1-7.

12. Beehner L. The Campaign to Ban Cluster Bombs. Backgrounder 2006.

13. US Department of Veterans Affairs. National Center for PTSD. 2016.

14. Kessler RC, Berglund $P$, Demler $O$, et al. Lifetime prevalence and age-of-onset distributions of DSM-IV disorders in the National Comorbidity Survey Replication. Arch Gen Psychiatry 2005;62:593-602.

15. VNCf P. Using the PTSD checklist for DSM-IV (PCL). 2014 https:// sph.umd.edu/sites/default/files/files/PTSDChecklistScoring.pdf

16. Yeager DE, Magruder KM, Knapp RG, et al. Performance characteristics of the posttraumatic stress disorder checklist and SPAN in Veterans Affairs primary care settings. Gen Hosp Psychiatry 2007;29:294-301

17. Bliese PD, Wright KM, Adler AB, et al. Validating the primary care posttraumatic stress disorder screen and the posttraumatic stress disorder checklist with soldiers returning from combat. J Consult Clin Psychol 2008;76:272-81.

18. Freedy JR, Steenkamp MM, Magruder KM, et al. Post-traumatic stress disorder screening test performance in civilian primary care. Fam Pract 2010;27:615-24.

19. Farhood L, Dimassi H, Lehtinen T. Exposure to war-related traumatic events, prevalence of PTSD, and general psychiatric morbidity in a civilian population from Southern Lebanon. J Transcult Nurs 2006;17:333-40.

20. Farhood LF, Fares S, Sabbagh R, et al. PTSD and depression construct: prevalence and predictors of co-occurrence in a South Lebanese civilian sample. Eur J Psychotraumatol 2016;7:31509.

21. Başoglu M, Livanou M, Crnobarić C, et al. Psychiatric and cognitive effects of war in former Yugoslavia: association of lack of redress for trauma and posttraumatic stress reactions. JAMA 2005;294:580-90.

22. Hall BJ, Hobfoll SE, Palmieri PA, et al. The psychological impact of impending forced settler disengagement in Gaza: trauma and posttraumatic growth. J Trauma Stress 2008;21:22-9.

23. de Jong JT, Komproe IH, Van Ommeren M, et al. Lifetime events and posttraumatic stress disorder in 4 postconflict settings. JAMA 2001;286:555-62.

24. Priebe S, Bogic M, Ajdukovic D, et al. Mental disorders following war in the Balkans: a study in 5 countries. Arch Gen Psychiatry 2010;67:518-28.

25. Ohry A, Rattok J, Solomon Z. Post-traumatic stress disorder in brain injury patients. Brain Inj 1996;10:687-96.

26. Shalev AY, Peri T, Canetti L, et al. Predictors of PTSD in injured trauma survivors: a prospective study. Am J Psychiatry 1996;153:219-25.

27. Mora AG, Ritenour AE, Wade CE, et al. Posttraumatic stress disorder in combat casualties with burns sustaining primary blast and concussive injuries. J Trauma 2009;66:S178-S185.

28. Shalev AY, Freedman S, Peri T, et al. Prospective study of posttraumatic stress disorder and depression following trauma. Am J Psychiatry 1998;155:630-7.

29. Greist J. Posttraumatic Stress Disorder (PTSD). Merck Manual. 2014 https://www.merckmanuals.com/professional/psychiatric-disorders/ anxiety-and-stressor-related-disorders/posttraumatic-stressdisorder-ptsd?qt=PTSD\&alt=sh

30. F. Farhood L. Patterns of psychiatric morbidity before and after a war in Lebanon at twelve months following cessation of hostilities. Open Psychiatr J 2014;8:1-9.

31. F. Farhood L. Patterns of Psychiatric Morbidity Before and After a War in Lebanon at Twelve Months Following Cessation of Hostilities. Open Psychiatr J 2014;8:1-9.

32. Holbrook TL, Hoyt DB, Coimbra R, et al. Long-term posttraumatic stress disorder persists after major trauma in adolescents: new data on risk factors and functional outcome. J Trauma 2005;58:764-71.

33. Holbrook TL, Hoyt DB, Stein MB, et al. Gender differences in longterm posttraumatic stress disorder outcomes after major trauma: women are at higher risk of adverse outcomes than men. J Trauma 2002:53:882-8.

34. Verger P, Dab W, Lamping DL, et al. The psychological impact of terrorism: an epidemiologic study of posttraumatic stress disorder and associated factors in victims of the 1995-1996 bombings in France. Am J Psychiatry 2004;161:1384-9.

35. Brewin CR, Andrews B, Valentine JD. Meta-analysis of risk factors for posttraumatic stress disorder in trauma-exposed adults. J Consult Clin Psychol 2000;68:748-66.

36. Ozer EJ, Best SR, Lipsey TL, et al. Predictors of posttraumatic stress disorder and symptoms in adults: a meta-analysis. Annual Meeting of the International Society for Traumatic Stress Studies; 14 Nov 1998 Washington, US:Educational Publishing Foundation,2008.

37. Freedman SA, Brandes D, Peri T, et al. Predictors of chronic posttraumatic stress disorder. A prospective study. Br J Psychiatry 1999;174:353-9.

38. Javidi H, Yadollahie M. Post-traumatic stress disorder. Int J Occup Environ Med 2011;3.

39. Farhood LF, Dimassi H. Prevalence and predictors for post-traumatic stress disorder, depression and general health in a population from six villages in South Lebanon. Soc Psychiatry Psychiatr Epidemiol 2012;47:639-49.

40. DiGrande L, Neria Y, Brackbill RM, et al. Long-term posttraumatic stress symptoms among 3,271 civilian survivors of the September 11, 2001, terrorist attacks on the World Trade Center. Am J Epidemiol 2011;173:271-81.

41. Fares J, Al Tabosh H, Saadeddin Z, et al. Stress, burnout and coping strategies in preclinical medical students. N Am J Med Sci 2016;8:75.

42. Fares J, Saadeddin Z, Al Tabosh H, et al. Extracurricular activities associated with stress and burnout in preclinical medical students. $J$ Epidemiol Glob Health 2016;6:177-85.

43. Vasterling JJ, Verfaellie M, Sullivan KD. Mild traumatic brain injury and posttraumatic stress disorder in returning veterans: perspectives from cognitive neuroscience. Clin Psychol Rev 2009;29:674-84.

44. Koren D, Norman D, Cohen A, et al. Increased PTSD risk with combat-related injury: a matched comparison study of injured and uninjured soldiers experiencing the same combat events. Am J Psychiatry 2005;162:276-28.

45. McAllister TW, Stein MB. Effects of psychological and biomechanical trauma on brain and behavior. Ann N Y Acad Sci 2010;1208:46-57.

46. Mollica RF, Henderson DC, Tor S. Psychiatric effects of traumatic brain injury events in Cambodian survivors of mass violence. $\mathrm{Br} \mathrm{J}$ Psychiatry 2002;181:339-47.

47. Hoge CW, McGurk D, Thomas JL, et al. Mild traumatic brain injury in US soldiers returning from Iraq. N Engl J Med 2008;358:453-63.

48. Schneiderman Al, Braver ER, Kang HK. Understanding sequelae of injury mechanisms and mild traumatic brain injury incurred during the conflicts in Iraq and Afghanistan: persistent postconcussive symptoms and posttraumatic stress disorder. Am J Epidemiol 2008;167:1446-52

49. Hasanović M, Pajević I. Religious moral beliefs as mental health protective factor of war veterans suffering from PTSD, depressiveness, anxiety, tobacco and alcohol abuse in comorbidity. Psychiatr Danub 2010;22:203-10.

50. Copeland-Linder N. Stress among black women in a South African township: the protective role of religion. J Community Psychol 2006;34:577-99.

51. Feder A, Ahmad S, Lee EJ, et al. Coping and PTSD symptoms in Pakistani earthquake survivors: Purposepurpose in life, religious coping and social support. J Affect Disord 2013;147:156-63.

52. Khamis V. Impact of war, religiosity and ideology on PTSD and psychiatric disorders in adolescents from Gaza Strip and South Lebanon. Soc Sci Med 2012;74:2005-11.

53. Johnson $\mathrm{H}$, Thompson $\mathrm{A}$. The development and maintenance of post-traumatic stress disorder (PTSD) in civilian adult survivors of war trauma and torture: a review. Clin Psychol Rev 2008;28:36-47. 
54. Gates MA, Holowka DW, Vasterling JJ, et al. Posttraumatic stress disorder in veterans and military personnel: epidemiology, screening, and case recognition. Psychol Serv 2012;9:361-82.

55. Jordan BK, Marmar CR, Fairbank JA, et al. Problems in families of male Vietnam veterans with posttraumatic stress disorder. J Consult Clin Psychol 1992;60:916-26.

56. Smith MW, Schnurr PP, Rosenheck RA. Employment outcomes and PTSD symptom severity. Ment Health Serv Res 2005;7:89-101.

57. Kulka RA, Schlenger WE, Fairbank JA, et al. Trauma and the Vietnam war generation: report of findings from the National Vietnam Veterans Readjustment Study: Brunner/Mazel, 1990.

58. Boscarino JA. Posttraumatic stress disorder and physical illness: results from clinical and epidemiologic studies. Ann N Y Acad Sci 2004;1032:141-53.

59. O'Toole BI, Catts SV, Outram S, et al. The physical and mental health of Australian Vietnam veterans 3 decades after the war and its relation to military service, combat, and post-traumatic stress disorder. Am J Epidemiol 2009;170:318-30.

60. Hoge CW, Terhakopian A, Castro CA, et al. Association of posttraumatic stress disorder with somatic symptoms, health care visits, and absenteeism among Iraq war veterans. Am J Psychiatry 2007;164:150-3.

61. Long N, MacDonald C, Chamberlain K. Prevalence of posttraumatic stress disorder, depression and anxiety in a community sample of New Zealand Vietnam War veterans. Aust N Z J Psychiatry 1996;30:253-6.

62. Karam EG, Fayyad J, Karam AN, et al. Outcome of depression and anxiety after war: a prospective epidemiologic study of children and adolescents. J Trauma Stress 2014;27:192-9. 